\title{
Türk edebiyatının Arap dünyasına tanıtımında Aynü’ş-Şems Üniversitesi’nin katkıları
}

\section{Yasin BEYAZ1}

\begin{abstract}
APA: Beyaz, Y. (2019). Türk edebiyatının Arap dünyasına tanıtımında Aynü'ş-Şems Üniversitesi’nin katkıları. RumeliDE Dil ve Edebiyat Araştırmaları Dergisi, (Ö5), 167-175. DOI: 10.29000/rumelide.606105.
\end{abstract}

\section{$\ddot{\mathbf{O} z}$}

\begin{abstract}
Mısır'daki Aynü'ş-Şems Üniversitesi, Türk Edebiyatı'nın Arap akademisine tanıtılmasında çok önemli katkılar sağlamıştır. Bu katkıda üniversitenin Türkçe Kürsüsü’nü kuran Yozgatlı İhsan Efendi’nin de önemli bir payı vardır. Aynü’ş-Şems Üniversitesi'nin kuruluşundan bugüne kadar Türk Edebiyatı ile alakalı birçok tez yapılmıştır. Tezler Türk Edebiyatçılarının eserleri üzerine tahlil ve tenkidler içerdiği gibi bu edebiyatçlların eserlerinden çeviriler de ihtiva etmektedir. Özellikle 20oo'li yıllardan sonraki tezlerde edebiyat incelemelerinin yanı sıra yazar ve şairlerin eserlerinin çevirilerine de yer verilmesi Türk Edebiyatı'nın Arap dünyasında bilinirliğini artırmıştır. Bu çalışmada Aynü’şŞems Üniversitesi’nin Türkçe Kürsüsü’nün nasıl kurulduğu, burada yazılan tezler, tezlerin içerikleri, bu tezlerin Türk Edebiyatı'nın Arap ilim ve kültür dünyasına ulaştırılmasındaki rolü ve bir çeviri dili oluşturma noktasındaki öneminden bahsedilecektir.
\end{abstract}

Anahtar kelimeler: Aynü’ş-Şems Üniversitesi, çeviri, Mısır, Türk edebiyatı, Yozgatlı İhsan Efendi.

\section{The contribution of Ain Shams University in the introduction of Turkish literature to Arap world}

\begin{abstract}
Ain Shams University in Egypt has made significant contributions to the introduction of Turkish Literature to the Arab Academy. Yozgatlı Ihsan Efendi, who established the Turkish Department of the university, has an important role in this contribution. Since the establishment of Ain Shams University, many studies have been carried out in Turkish Literature. The theses include analyses and criticisms on studies of Turkish writers as well as translations from the studies of these writers. Especially in the theses after the 2000s, besides literature reviews, the translation of the studies of authors and poets has increased the recognition of Turkish Literature in the Arab world. In this study, it will be mentioned how the Turkish Department of Ain Shams University was established, the theses were written here, the contents of these theses, the role of theses in conveying the Turkish Literature to the world of Arab science and culture and the importance of creating a translation language.
\end{abstract}

Keywords: Ain Shams University, translation, Egypt, Turkish literature, Yozgatli Ihsan Efendi.

\section{Giriş}

Aynü’ş-Şems Üniversitesi 1950 yllında “İbrahim Paşa” ismiyle kurulmuştur. 23 Temmuz 1952 askeri darbesinden sonra Mısır'daki üniversitelerin Mısır tarihiyle alakalı isimler almasına karar verilmiş ve 21

1 Dr. Öğr. Üyesi, Yalova Üniversitesi, İslami İlimler Fakültesi, Türk İslam Edebiyatı Bölümü (Yalova, Türkiye), yasinbeyaz80@hotmail.com, ORCID ID: oooo-0002-9086-1458 [Makale kayıt tarihi: 17.04.2019-kabul tarihi: 18.08.2019; DOI: 10.29000/rumelide.606105] 
Şubat 1954 yllında üniversitenin ismi "Helyopolis" olarak değiştirilmiştir. Aynı sene içerisinde "Helyopolis” ismi de değiştirilerek bunun Arapça karşılı̆̆ olan "Aynü’ş-Şems” ismi verilmiştir. Üniversitenin amblemi de hem tarih hem de bilime atfen iki kartal arasında dikilitaştır. Üniversite, Kahire/Fuadü'l-Evvel (Birinci Fuad) ve İskenderiye/Faruku'l-Evvel (Birinci Faruk) üniversitelerinden sonra Mısır’ın en eski üçüncü üniversitesidir. Aynü’ş-Şems üniversitesinin rektörlüğü Hıdiv İsmail döneminde inşa edilen “Kasrü’z-Za’ferân (Zaferan Sarayı)”dadır.²

Aynü’ş-Şems Üniversitesi 1950 yılında sekiz fakülte ile eğitime başlamıştır. Bu fakültelerin isimleri şöyledir: Edebiyat, Hukuk, İktisat, Ticaret/İktisat, Fen Bilimleri, Mühendislik, Tıp, Ziraat ve Kızlara Mahsus Fakülte. Daha sonra bu fakültelere yenileri eklenerek toplamda 16 fakülte ve üç enstitüyle eğitim hayatına devam etmiştir. 3 İlk kurulan fakültelerden olan Edebiyat Fakültesi'nin Bölümlerinden birisi de Şark Dilleri ve Edebiyatları Bölümü’dür. Bu bölüm; Farsça, Türkçe ve Urdu dillerinden oluşmaktadır.4

\section{Aynü'ş-Şems Üniversitesi'nin Şark Dilleri Bölümü’nde Türkçe kürsüsü}

Yukarıda da belirttiğimiz gibi Edebiyat Fakültesi 1950 yılında kurulan Aynü’ş-Şems Üniversitesi’nin ilk fakültelerinden biridir. Şark Dilleri Bölümü'yse bu fakültenin çatısı altında kurulmak istenen bölümlerdendir. Bu bölümde Farsça, Türkçe ve İbranice Kürsüleri olacaktır. ${ }^{5}$ Şark Dilleri Bölümü’nün başına Akif'in Kral Fuad Üniversitesi’nden öğrencisi Farsça profesörü İbrahim Emin eş-Şevârîbî getirilmiştir. Eş-Şevârîbî, yakın dostu olan Yozgatlı İhsan Efendi'den bölümün Türkçe Kürsüsü'nü kurmasını istemiștir. İhsan Efendi bu teklife olumlu karşlık vererek 1951 yllında bu kürsünün temellerini atmış ve on yl boyunca bu görevi hakkıyla yerine getirmiştir. "Peder merhumun önemsediği hususları not etme alışkanlığı vardı. İşte bu göreve başlamasını 'Cenab-ı hakkın inayetiyle bugün Cumartesi 21Rebiulahir 1371 (19 Ocak 1952) günü derslerime başladım ve ilk iki dersimi 9-10, 10-11 saatleri arasında verdim.' diye bir not düşmüştür.” (İhsanoğlu, 2018; s. 156-157) Bu notun devamından anladığımız kadarıyla kürsünün müfredatı belli bir vakit almış ve eğitim-öğretim tam anlamıyla yaklaşık olarak bir yll sonra başlamıştır. İhsan Efendi, öğrencilerin dil ve edebiyat yanında tarih yönünden de gelişmelerini sağlamak maksadıyla geniş kapsamlı bir program hazırlamıştır. Bundan dolayı da programa Türk ve Osmanlı tarihiyle alakalı dersler de ilave etmiştir. Bu derslerin hasılası hazırlanan tezlerde kendini göstermiştir. Aşağıda da göreceğimiz gibi Türkçe Kürsüsü’nde Osmanlı tarihine dair tezler yapılmıştır.

Açılan bu kürsüde dersleri verecek hoca sayısının az olması nedeniyle İhsan Efendi başta Osmanlı Türkçesi dersleri olmak üzere birçok derse girmek zorunda kalmıştır. İhsan Efendi’nin öğrencilerinden Abdülkadir Şener'in ifadeleri de bu yöndedir (Şener, 1985: s. 385). Onun öğrencilerinden bir kısmı daha sonra bu kürsüde hoca olarak ders verecekler ve 1985 yılında hocaları adına bir sempozyum

http://www.asu.edu.eg/ar/17/page (Erişim tarihi: 11.03.2019).

http://www.asu.edu.eg/ar/17/page (Erişim tarihi: 11.03.2019).

Ancak üniversitenin resmi sitesinde Urdu dili yerine sehven Avrupa dilleri yazılmış olsa gerektir. Çünkü Külliyetü'lElsine/Diller Fakültesi'nde Şark İslam Dilleri Bölümü vardır ve bu bölümde; Türkçe, Farsça ve Urduca yer almaktadır (Bkz: http://alsun.asu.edu.eg/article.php?action=show\&id=57\#.XIrCNiIzbix. Erișim tarihi: 14.03.2019).

Her ne kadar Türkçe Kürsüsü ilkin Edebiyat Fakültesi bünyesinde eğitime başlamışsa da daha sonra 1989-1990 eğitim öğretim yılında kurulan Külliyetü’l-Elsine/Diller Fakültesi’nde de bir Türkçe Kürsüsü açılmıştır. Bu kürsü fakültenin İslam Şark Dilleri Bölümü’ne aittir. Bu bölümde Türkçe haricinde Farsça ve Urduca kürsüleri de yer almaktadır. Anladığımız kadarıyla Edebiyat Fakültesi’ndeki Şark Dilleri ve Edebiyatları Bölümü’ndeki kürsüye ilaveten burada da bir kürsü açılmıştır (Bkz: http://alsun.asu.edu.eg/article.php?action=show\&id=57\#.XIrOPiIzbiy. Erişim tarihi: 14.03.2019). 
düzenleyeceklerdir (Şener, 1985; s. 385-390). Bu öğrencilerden Hüseyin Mucib el-Mısri, Türk Edebiyatı araştırmaları noktasın ciddi çalışmalar yapacak ve kitaplar neşredecektir. ${ }^{6}$

Üniversitenin Türkçe Kürsüsü, Yozgatlı İhsan Efendi tarafından hazırlandığı gibi dersler de aynı ciddiyetle verilmiştir. Bu bağlamda verilen eğitimin kalitesini İhsan Efendi’nin 1960 yll 4. Sinıf öğrencilerine hazırladı̆̆ imtihan sorularından anlamak mümkündür. "Mısır'daki yıllarımdan hatırladığım mumlu kağıt tekniğiyle çoğaltılan bu imtihan kağıdında beş soru yer almaktadır. İki seçenekli ilk soru kompozisyon sorusudur. Türkçe bir kompozisyon yazılmak üzere seçilmesi istenen mevzuların ilki, imtihana giren öğrencilerin 'Türkçe öğrenmeyi niçin intihap ettiklerini' izah etmelerini istemektedir. Kelime ve cümle bilgisini ölçmeyi amaçlayan 2. soruda 'çalışıyor, yazamadım, uçak, tuzak, başvekil, başkan, coşkun, sokak, yıl, yllan' kelimeleri verilmiş ve bunların manalı Türkçe cümlelerle kullanılması istenmiştir. 3. soruda ise imtihan kağıdında Arap harfleriyle verilen, aşağıya alıntıladığım beyitlerin düzyazıya çevrilmesi ve Arapça olarak izah edilmesi istenmektedir... Bir sonraki soruda ise Arap harfleriyle verilen 6 cümlenin olumsuzlarının yazılması ve Arapça anlamlarının izah edilmesi istenmektedir... İmtihan kağıdında Mehmet Akiften bahseden bir paragrafı bu defa Latin harfleriyle vererek bunun Arapçaya tercüme edilmesini istemesi kanaatime göre dikkate değer bir husustur." (İhsanoğlu, 2018; s. 158-159)

Üniversitenin resmi internet sitesindeki bilgilere göre Doğu Dilleri ve Edebiyatları Bölümü’ndeki öğrenciler ilk iki seviye/dönemden sonra istedikleri bir kürsüyü tercih edebilmektedir. İlk iki seviyede Farsça, Arapça, Türkçe ve Urduca derslerinin tamamını alan öğrenciler üçüncü seviye itibariyle tercih ettikleri kürsülere göre zorunlu ve seçmeli dersler almaktadır. Toplam sekiz seviye/dönemden oluşan bu Türkçe Kürsüsü’nün dersleri dönemlere göre şöyledir:

Üçüncü Seviye/dönem Zorunlu Dersler: Farsça, İnşa ve Dil Uygulamaları, Anadolu Selçukluları, Araştırma Yöntemleri, Türk Dil Bilimleri, Arap Edebiyatı (Edebî Tenkid Nazariyesi).

Seçmeli Dersler: Tercümeye Giriş, Türkiye'de İslam Tasavvufu Metinleri.

Dördüncü Seviye Zorunlu Dersler: Türk Lehçeleri, Tanzimat’a Kadar Türk Edebiyatı, Metinlerle Osmanlı Devleti Tarihi, Modern Avrupa Dilleri (İngilizce, Fransızca).

Seçmeli dersler: Türk Edebiyatı'nın Kaynakları, Türk İslam Sanatları.

Beşinci Seviye Zorunlu Dersler: Farsça, Yeni Türk Edebiyatı, Metinlerle Osmanlı Devleti Tarihi, Osmanlı Vesikaları, Arapça (Edebî Metin Tahlili)

Seçmeli dersler: Osmanlı Yazmaları, Türk Tarihi Kaynakları.

Altıncı Seviye Zorunlu Dersler: Türkçeye ve Türkçeden Çeviri, Türk Lehçeleri, Çağdaş Türk Edebiyatı, Metinlerle Yeni ve Modern Türk Tarihi, Avrupa Dilleri (İngilizce, Fransızca).

Seçmeli dersler: Yeni Türk Tiyatrosu, Modern Türk Hikayesi.

\footnotetext{
6 Hüseyin Mucib el-Mısri daha sonra Arapça olarak Türk edebiyatına dair çok ciddi çalışmalar yapmıştır. Ayrıca onun Arap, Türk ve Fars edebiyatlarını karşılaştıran eserleri de vardır (Bkz: Hüseyin Mucib el-Mısri, Tarihu'l-Edebi’t-Türkî, Daru'sSekafe't-Türkî, Kahire 200; Min el-Edebi'l-Furs ve't-Türk, Mektebetü'l-Camiatü'l- Fuadü'l-Evvel, Kahire). 
Yedinci Seviye Zorunlu Dersler: İhtisas Tercümesi (Siyasî-Askerî), Türkçe Makale Yazma, Modern ve Çağdaş Türk Basın Edebiyatı, Arapça (Karşılaştırmalı Edebiyat Nazariyesi).

Seçmeli dersler: Arapçadan Türkçeye Çeviri, Türkçe Çeviri Problemleri.

Sekizinci Seviye Zorunlu Dersler: İhtisas Tercümesi (İktisadî-İlmî), Halk Edebiyatı, Orta Asya'da Türk Edebiyatı, Karşılaştırmalı Türk Edebiyatı, Türkçe Makale Yazma, Modern Avrupa Dilleri (İngilizce, Fransizca).

Seçmeli dersler: Arapçadan Türkçeye Çeviri, Arapça ve Türkçenin İlişkisi.

Yukarıda vermiş olduğumuz müfredatta görüldüğü üzere özellikle altıncı dönemden sonra ciddi anlamda çeviri dersleri vardır. Bu dersler Türkçe Kürsüsü'nde önemli bir yere sahiptir. Bunlar sayesinde Türkçe Kürsüsü’nde hazırlanan tezlerde öğrencilere çeviri yapma becerisi kazandırılmıştır. Ders programında dikkatimizi çeken başka bir şey de Osmanlı ve Türk tarihiyle alakalı derslerin yer almasıdır.

\section{Türk edebiyatı alanında yapılan bazı tezler}

Aynü’ş-Şems Üniversitesi Şark Dilleri Bölümü’nde 2000 yllına kadar yapılan tezleri incelediğimiz zaman bu tezlerin genel anlamda araştırma ve incelemeye yönelik olduğunu görmekteyiz. Türkçe Kürsüsü kurulduktan sonra elde yeterli materyal olmadığı için ilk dönemde genel anlamda edebiyatımıza dair bir birikim oluşturulması hedeflenmiştir. Bu bağlamda da yüksek lisans ve doktora tezleri daha çok edebiyatçılarımızın hayatları ve eserleri üzerine yoğunlaşmıştır. Bundan dolayı "Namık Kemal Hayatı ve Eserleri”, "Recazide Ekrem Hayatı ve Eserleri” ya da "Şeyh Galip Hayatı ve Eserleri” gibi daha çok şahıs odaklı tezler hazırlanmıştır. Bunlara ek olarak "Tanzimat Edebiyatı'nda Köy ve Kasaba Kavramları”, “Ziya Gökalp’in Edebiyatında Milliyetçilik”, “Tevfik Fikret’te Sembolizm” gibi konu merkezli tezler de yazılmıştır. Yazılan bu tezlerden yola çıkarak 1950-2000 arasındaki dönemi daha çok birikim ve oluşum dönemi şeklinde isimlendirebiliriz.

\subsection{0o'den önceki tezler:}

1-Muhammed Abdüllatîf Herîdî, Nâmık Kemâl Hayâtuhu ve Âsâruhu (Namık Kemal Hayatı ve Eserleri), Master Tezi, 1972.7

2-el-Safsâfî Ahmed el-Mursî, El-Edebü'l-Masrahî inde Abdulhak Hâmid ve Te'sîrihi fi'l-Edebi'lMesrahi't-Türkî (Abdülhak Hamid'in Tiyatro Eserleri ve Türk Tiyatrosuna Tesiri), Master Tezi, 1974.

3-Abd el-Münsaf Mecdi Bekr, İbrahim Şinasi Efendi Hayatuhu ve Âsâruhu (İbrahim Şinasi’nin Hayatı ve Eserleri), Master Tezi, 1976.

4-Aziz Abdurrahman es-Sâvî, El-Kavmiyye fil Edebi Ziya Gökalp (Ziya Gökalp’in Edebiyatında Milliyetçilik), Master Tezi, 1977.

\footnotetext{
$7 \quad$ Buradaki ilk 17 tez için Süleyman Özbek’in makalesinden yararlanılmıştır (Bkz: Süleyman Özbek, "Mısır Arap Cumhuriyeti Ayn-Şems Üniversitesi Edebiyat Fakültesinde Türkoloji Sahasında Yapılmış Master-Doktora Tezleri II”, Tarih
} Araştırmaları Dergisi, s. 291-304. 
5-Fuad Ahmed es-Seyyid Kamil, Muallim Naci Hayatuhu ve Âsâruhu (Muallim Naci'nin Hayatı ve Eserleri), Master Tezi, 1981.

6-Hamide İbrahim İvaz, Eş-Şi'rü’l-Kavmî inde Mehmed Emin (Mehmet Emin'de Milliyetçilik Şiirleri), Master Tezi, 1983.

7-Reşâd Muhammed Hâmis, Eş-Şi'rü'l-Rebâb fi'l-Anadol fi'l-Karnu's-Sâbi'a Aşar ve Karacaoğlan Raidü'ş-Şi'rü'ş-Şa'bi't-Türkî (17. Yüzyılda Anadolu Saz Şiiri ve Türk Halk Şiirinin Öncüsü Karacaoğlan), Master Tezi, 1983.

8-Seniyye Muhammed Mustafa, El-Hayatü'l-İctimaiyye fi Türkiye min Hilâli Rivâyâti Yakup Kadri Ankara ve Panorama 1-2 (Yakup Kadri'nin Ankara ve Panorama Romanlarında Türkiye'de İctimâî Hayat), Master Tezi, 1983.

9-Abdurrezzak Muhammed Hasan Berekât, El-Hallac fi'ş-Şiri'l-Arabî ve't-Türkîll-Hadîs (Yeni Türk ve Arap Şiirinde Hallac), Master Tezi, 1983.

10-Sonya Zekeriyya Ahmed, Dirâsetü Tahliliyye ve Nakdiyye Li'l-Kıssatü'l-Kasîre inde Ömer Seyfeddin (Ömer Seyfettin’in Hikayeleri Üzerine Analitik ve Eleştirel Bir Çalışma), Master Tezi, 1984.

11-Mecdi Salah el-Mahlûf, Eş-Şairü't-Türkî Mehmed Akif ve Âsâruhu (Türk Şair Mehmed Akif ve Eserleri), Master Tezi.

12-Mecdi Salah el-Mahlûf, Er-Remz inde Tevfik Fikret (Tevfik Fikret’te Sembol(izm), Master Tezi.

13-Fethi Abd el-Mûtî el-Neklâvî, Er-Rivâyetü'l-Türkiyetü'l-Hadise münzü Bidâyetü'l-Karni'l-İşrîn hatta'l-İnkılâbi'l-Luğavi'l-Kemâlî (Yirminci Yüzyılın Başından Kemalizmin Harf Devrimine Kadar Modern Türk Romanı), Doktora Tezi, 1975.

14- Muhammed er-Reşid Muhammed Süleyman, Kemal Paşazade Şâiren (Şair Kemalpaşazade), Doktora Tezi, 1984.

15- El-Medâihü’n-Nebeviyye fi'l-Edebi't-Türkî (Türk Edebiyatında Peygamber Methiyeleri/Naatlar), Doktora Tezi 1985.

16-El-İğtirâb fi'ş-Şiri’t-Türkî'l-Muâsır ve'ş-Şirü’l-Arabî fî Külli min Mısr ve'ş-Şam ve'l-Irak maba'de ElHarbü'l-Âlemiyyetü's-Sâniye (İkinci Dünya Harbi Sonrasında Muasır Türk ve Arap (Mısır, Şam ve Irak) Şiirinde Gurbet), Doktora Tezi, 1986.

17- Es-Sefsâfî Ahmed el-Mursî, Et-Te'sirü’l-Arabî fî Âsâri Ziya Paşa ve Namık Kemal ve Ali Suavi (Ali Suavi, Namık Kemal ve Ziya Paşa'nın Eserlerinde Arap Tesiri), Doktora Tezi.

18-Ahmed Fuad Mütevelli, Şair Nedim Hayatı ve Eserleri. ${ }^{8}$

19-Muhammed Seyyid Süleyman, Abdülhamid Ziya Paşa Hayatı ve Eserleri.

18-43 arasındaki tezler için Abdülkadir Şener’in makalesinden yararlanılmıştır. (Bkz: Abdulkadir Şener, Mehmed İhsan Abdülaziz İslam ve Şarkiyat Araştırmaları Semineri, Dokuz Eylül İlahiyat Fakültesi Dergisi, 1985, sayı 2, s. 387-390. 
20- Amr Muhammed Abdülbaki, Şair Şeyhi Hayatı ve Eserleri.

21-Salih Sa'davi, Şeyh Galip Hayatı ve Eserleri.

22- Muhammed Harb Abdulhamid, Yeni Türk Edebiyatı.

23- Abdulaziz Muhammed Ivadullah, İslam Edebiyatında Leyla ve Mecnun (Arap-Türk ve İran Edebiyatlarında Karşılaştırmalı Bir Çalışma).

24- Muhammed Şelebi, Yahya Bey’de Hamaset.

25-Reşad Hamis, 16. ve 17. Yüzyllarda Türk Halk Edebiyatı.

26-Zeynep Sa’d Zağlul, Recaizade Ekrem Hayatı ve Eserleri.

27- Semir Abbas, Şair ve Nasir Olarak Lamii.

28-Fatıma Zehra Muhammed İsa, Şair Süleyman Çelebi, Çağı ve Eserleri.

29-İman Muhammed İsa, Ahmedi ve Süleyman Savcı'da Cemşid ve Hurşid Hikayesi.

30-Ahmed Afifi Huseyn, Halid Ziya'nın Romanlarına ve Küçük Hikayelerine Göre İstanbul'da İctimai Hayat.

31-Huveyd Allam, Şair Ahmed Paşa.

32- Faize Fuad Eş-Şafii, Nabi'nin Gazelleri.

33- Muhammed Hureydi, Tanzimat Edebiyatında Köy ve Kasaba Kavramları.

34- Muhammed Süleyman, Şair Olarak Kemalpaşazade.

35-Azze Abdurrahman es-Savi, Necip Fazıl’ın Edebiyatında İslamcı Eğilim.

36-Amr Abdulbaki, Ahmedi’nin İskendernamesi.

37-Huseyn Mucib el-Mısri, Türk Şiiri’nin Emiri Fuzuli.

38-Reşad Hamis, Seyyid Battal Gazi Destanı.

39-Abdurrazik Hasan Berekat, Yeni Türk ve Arap Şiirinde Batılılaşma.

40- Hamide İbrahim, Faruk Nafiz ve Milliyetçi Edebiyat.

41- Muhammed Şelebi, Türk Atasözleri (Karşılaştırmalı Bir Çalışma).

42-Zeynep Sa’d Zağlul, Türk Kadın Şairler.

43-Seniye Muhammed Mustafa, Peyami Safa'nın Biz İnsanlar ve Bir Tereddüdün Romanı Adlı Romanlarının Tenkidine Dair Bir Araştırma. 


\section{0o'den sonraki tezler:}

İlk elli yıllık dönem içerisinde ortaya çıkan edebî birikimin ardından 200o'li yılardan sonra akademik çalışmalarda daha fazla ihtisaslaşma dikkati çekmektedir. Tezler genel anlamda bir konuya veya edebiyatçının hayatı ve eserlerine değil herhangi bir eserinin üzerine yoğunlaşmıştır. Örneğin "Necati Cumalı'nın Tütün Zamanı Romanında Taşra'nın Resmedilişine Eleştirel Bir Yaklaşım ve Romanın Arapça Tercümesi” isimli tezde Necati Cumali'nin bütün eserleri yerine bir eseri merkeze alınmıştır. Bunda yukarıda da bahsettiğimiz gibi oluşturulan edebî birikimin payı büyüktür. Konulardaki bu ihtisaslaşma akademik çalışmalara farklı bir boyut daha kazandırmış ve tezlerde edebiyatçıların eserlerinden çeviriler de yapılmıştır. Bu çeviriler sayesinde Arapçada ciddi bir Türk edebiyatı çevirisi birikimi meydana gelmiş ve Türkçeden Arapçaya bir çeviri dili oluşmuştur. Tezlerde çeviri metinlerin yer alması sadece Aynü’ş-Şems Üniversitesi'nde değil İskenderiye Üniversitesi’nde de hemen hemen aynı dönemde başlamıştır. ${ }^{9} \mathrm{Bu}$ dönemde zikredeceğimiz diğer önemli şey de artık hazırlanan tezlerin hiçbirinin tarihle alakasının olmaması ve tamamen edebiyat merkezli olmasıdır.

Mısır'daki Üniversitelerde yapılan bu tezler sayesinde Türkçeden Arapçaya (bir çeviri dili oluşturulduğu için) çevirilerde sıkıntı yaşanmazken modern dönemde ortaya konan herhangi bir Arapça eserin Türkçeye aktarımında ciddi sıkıntılar baş göstermiştir. Bunda (Hadis, Kelam, Tefsir vb. dini metinler hariç) Arapça çeviri dilinin oluşturulamamasının payı büyüktür. Arap edebiyatçların eserlerinin Türkçeye çevirisinde çok fazla zorluklar yaşandığ 1 için bu eserler İngilizceden Türkçeye çevrilmektedir.10 Necip Mahfuz’un bazı romanlarının İngilizceden dilimize aktarılması buna iyi bir örnektir.

\section{2ooo'den sonra yapılan tezler şunlardır:}

1-Şâhinâz Midhad Nâfi' Emîn, Sûretü’r-Rîf fî̀ Rivâyeti Mevsimü’t-Tibğ li-Necâti Cumali li-Dirâseti'nNakdiyye maa Tercetü'r-Rivâye ile'l-Arabiyye (Necati Cumalı'nın Tütün Zamanı Romanında Taşra'nın Resmedilişine Eleştirel Bir Yaklaşım ve Romanın Arapça Tercümesi), Master Tezi, 2017.

İki bölümden oluşan bu tezin ilk bölümünde romandan hareketle taşradaki siyasî, iktisadî ve ictimâî hayat ele alınmıştır. İkinci bölümdeyse romanın sanatsal ve edebî incelemesi yapılmıştır. Burada romanın anlatım özellikleri, zaman, mekan, şahıs kadrosu, dil ve üslubu ele alınmıştır. Bu bölümün ikinci kısmındaysa romanın tercümesine yer verilmiştir. ${ }^{11}$

9 İskenderiye Üniversitesinde bu bağlamda yapılan tezlerden bazıları şunlardır: İman Ahmed Muhammed Şeybûb, "ElMecmûatü'l-Kısasiyye İhtiyar Çilingir/Sâni'ü'l-Mefâtihü'l-Acûz li'l-Kâtibi't-Türkî Memduh Şevket Esendal Dirâsetün Tahlîliyyetün Nakdiyye maa Tercemeti Nemâzicin Muhtâra (Memduh Sevket Esendal'ın Toplu Hikayeleri İhtiyar Çilingir: Bazı Seçilmiş Örnek Tercümelerle Birlikte Tahlil ve Tenkidi, Master Tezi, 2016, Mustafa Fuad Muhammed Abdussamed, “el-Mecmûatü'l-Kısâsiyye Gurbet Hikayeleri/Hikâyâtü’l-Gurbe li’i-Edîb’t-Türkî Refik Halid Karay Dirâsetün Edebiyye ve Terceme” (Refik Halid Karay’ın Toplu Hikayeleri Gurbet Hikayeleri: Edebî Çalışma ve Tercümesi), Master Tezi, 2015; Nurhan Emin Ali Abdulazim, "el-Menfâ beyne'l-Hakîka ve'l-Mecâz fî Rivâyeti Türkkiyeti'l- Hadîse, Rivâyeti Menfâ liYakup Kadri Karaosmanoğlu Nümuzecen Terceme ve Dirâsetün Nakdiyye" (Modern Türk Romanında Mecaz ve Gerçek Arasında Sürgün ve Yakup Kadri’nin Sürgün Romanının Bu Bağlamda Eleştirisi ve Tercümesi), Master Tezi, 2017; Muhammed Sitkı İbrahim Ali, "el-Kazâya'l-İctimaiyye fì Masrahiyyeti Ferh fi'l-Makhâ li'l-kâtibi't-Türkî Sabahattin Kudret Aksal: Dirâsetün Nakdiyyetün ve Terceme” (Sabahattin Kudret Aksal'ın Kahvede Şenlik Var Adlı Tiyatrosunda Toplumsal Sorunlar: Edebî Eleştirisi ve Tercümesi, $2018 . \quad$ Bkz. http://eulc.edu.eg/eulc_v5/Libraries/start.aspx?fn=ApplySearch\&SearchId=8344754\&frameName=\&PageNo=4\&Page Size $=10$ Erişim tarihi: 15.03 .2019 ).

10 Örneğin Necip Mahfuz’ın Miramar romanı Yusuf Peker tarafindan İngilizceden Türkçeye aktarılmıştır (Bkz: Necip Mahfuz, Miramar, Kırmızı Kedi Yayınları, İstanbul 2017). Aynı şekilde Mahfuz’un Midak Sokağı isimli eseri Güler Dikmen tarafından İngilizceden Türkçeye Ara Sokak adıyla tercüme edilmiştir. (Bkz: Necip Mahfuz, Ara Sokak, Hürriyet Yayınları, İstanbul 1977).

11

http://eulc.edu.eg/eulc_v5/Libraries/Thesis/BrowseThesisPages.aspx?fn=ThesisPicBody\&BibID=12511457\&TotalNoOf Record $=551 \&$ PageNo=11\&PageDirection=previous (Erişim tarihi: 15.03.2019). 
2- Âtıf Hasan en-Nühhâs, El-Vâkııye fî Rivâyeti Sandıklı Bakkâl li’i-Edebîhi Halide Edip Adıvar: Terceme ve Tahlil (Halide Edip Adıvar'ın Sinekli Bakkal Romanında Gerçekçilik: Tercüme ve Tahlil), Master Tezi, 2002.

3-Muhammed Abdülğanî İbrahim Selim, Meşâkîlü’t-Tufûle fî̀ Muhtârâtin min A'mâli Kemaleddin Tuğcu: Direseü’n-Nakdiyye Üslûbiyye (Kemalettin Tuğcu'nun Eserlerinden Seçmelerde Çocukluk Sıkıntıları: Üslub Yönünden Eleştiri), Doktora Tezi, 2015.

Tez üç bölümden oluşmaktadır. Birinci bölümde Kemalettin Tuğcu'nun romanlarında ele aldığı üslub meseleleri incelenmektedir. İkinci bölümde Kemalettin Tuğcu'nun romanlarındaki ahlaki kıymetler konu edilmiştir. Üçüncü bölüm ise Tuğcu'nun eserlerinin sanatsal değerlendirmelerini kapsamaktadır.

4- Reşâ Abdü'l-Âl Mahmud Said, el-Vâkniyye fî Rivâyeti inde Sabahaddin Ali maa Tercemeti Rivâyeti Yusuf Kuyucaklı (Sabahattin Ali’nin Kuyucaklı Yusuf Romanında Gerçekçilik ve Romanın Tercümesi), Master Tezi, 2015.

Tez üç bölümden oluşmaktadır. Birinci bölümde Sabahattin Ali ve dönemi ele alınmaktadır. Burada Sabahattin Ali'nin yaşadığı dönemdeki siyasî ve edebî ortam, onun edebî düşüncesinin oluşumu ve toplumsal gerçekçi görüşü incelenmiştir. İkinci bölümde Kuyucaklı Yusuf romanının içeriği incelenmiştir. Üçüncü bölümdeyse eser edebî ve sanatsal yönden tahlil edilmiştir. Bunun ardından Kuyucaklı Yusuf un tercümesine yer verilmiştir.

\section{Sonuç}

Kahire ve İskenderiye Üniversitelerinden sonra Mısır'ın en eski üçüncü üniversitesi olan Aynü’ş-Şems Üniversitesi'nde 1951 yılında Şark Dilleri ve Edebiyatları Bölümü'nde Türkçe Kürsüsü kurulmuştur. Bu kürsünün kurucusu Yozgatlı İhsan Efendi'dir. İhsan Efendi, Türkçe Kürsüsü'nün ders programını hazırlarken öğrenciler geniş bir ufuk kazansınlar diye Türk dili ve edebiyatı dersleri yanında Osmanlı tarihiyle alakalı dersler de koymuştur. Bundan dolayı burada yazılan tezlerin büyük çoğunluğu Türk Edebiyatı'na dair araştırma-incelemeler olsa da bazıları da Osmanlı tarihi ile alakalıdır. Kuruluşundan bugüne burada hazırlanan tezler Arap ilim ve kültür aleminin Türk Edebiyatı hakkında bilgilenmesine kaynak olmuştur. İlk elli yıllık dönem boyunca Mısır'daki Türk Edebiyatı çalışmaları için akademik bir materyal birikimi oluşturan Aynü’ş-Şems Üniversitesi birikim ve oluşum görevini yerine getirdikten sonra (38 Yüksek Linsans ve 5 Doktora Tezi) bir adım daha atmıştır. Bu adım da tezlerde Türk Edebiyatı'ndan çevirilerin yer almasıdır. Türkçe Kürsüsü’nün son dönemlerde yapılan tezlerine araştırma ve incelemelere ek olarak çalışılan edebiyatçlların eserlerinden bir kısmının ya da tamamının çevirileri de tezlerde yer almıştır (3 Yüksek Lisans ve 1 Doktora Tezi). Tezlere bu çevirilerin konması Mısır'da Türkçe Kürsüsü olan diğer üniversitelere örnek olmuş ve çevirilerin ilave edildiği tezler son dönemde yaygınlık kazanmıştır. Bu çalışmalar sayesinde Türkçeden Arapçaya bir çeviri dili oluşturulmuş ve Türk Edebiyatı'na ait eserler Arapçaya çevrilmiştir. Bu birikimin oluşmasında başta Aynü’ş-Şems Üniversitesi olmak üzere diğer üniversitelerin büyük katkısı olmuştur.

\section{Kaynakça}

http://www.asu.edu.eg/ar/17/page (Erişim tarihi: 11.03.2019).

http://alsun.asu.edu.eg/article.php?action=show\&id=57\#.XIrCNiIzbix. Erişim tarihi: 14.03.2019). http://alsun.asu.edu.eg/article.php?action=show\&id=57\#.XIrOPiIzbiy. Erişim tarihi: 14.03.2019). 
İhsanoğlu, E. (2018). Kaybolan Dünyadan Nurlu Bir Sima Yozgatl İhsan Efendi, İstanbul: Doğan Kitap.

http://arts.asu.edu.eg//uploads/arts/3-YYYYYY-YYYYYYY_201509039107.pdf (Erişim tarihi: 11.03.2019).

Özbek, S. Mısır Arap Cumhuriyeti Ayn-Şems Üniversitesi Edebiyat Fakültesinde Türkoloji Sahasında Yapılmış Master-Doktora Tezleri II. Tarih Araştırmaları Dergisi. s. 291-304.

http://eulc.edu.eg/eulc_v5/Libraries/start.aspx?fn=ApplySearch\&SearchId=8344754\&frameName=\& PageNo=4\&PageSize=10 Erişim tarihi: 15.03.2019).

Mahfuz, N. (2017). Miramar. İstanbul: Kırmızı Kedi Yayınları.

http://eulc.edu.eg/eulc_v5/Libraries/Thesis/BrowseThesisPages.aspx?fn=ThesisPicBody\&BibID=125 11457\&TotalNoOfRecord $=551 \&$ PageNo=11\&PageDirection=previous (Erişim tarihi: 15.03.2019).

Şener, A. (1985). Mehmed İhsan Abdülaziz İslam ve Şarkiyat Araştırmaları Semineri. Dokuz Eylül İlahiyat Fakültesi Dergisi. sayı 2, s. 385-390.

el-Mısri, H. M. (2000). Tarihu'l-Edebi't-Türkî. Kahire: Daru's-Sekafe’t-Türkî.

el-Mısri, H. M. Min el-Edebi'l-Furs ve’t-Türk. Kahire: Mektebetü’l-Camiatü’l- Fuadü'l-Evvel.

Necip Mahfuz, Ara Sokak, Hürriyet Yayınları, İstanbul 1977. 